\title{
Perancangan Desain Inovasi Pada Mesin Produksi Kue Pudak Berbasis Prioritas Keinginan Konsumen Dengan Metode QFD dan AHP
}

\author{
Muharom $^{1)}$, Siswadi $^{2)}$ \\ ${ }^{122)}$ Teknik Mesin, Universitas Wijaya Putra \\ E-mail: ${ }^{1)}$ muharom@uwp.ac.id, ${ }^{2)}$ siswadi@uwp.ac.id
}

\begin{abstract}
Abstrak
Usaha Mikro Kecil dan Menengah (UMKM) kue Pudak Di Gresik sangat banyak jumlahnya, namun UMKM tersebut memiliki beberapa permasalahan salah satunya yaitu dalam proses produksinya rata-rata belum tersentuh Teknologi Tepat Guna (TTG) sehingga pertumbuhannya kurang maksimal karena masih dilakukan secara manual. Tujuan dari penelitian ini yaitu merancang desain mesin produksi pudak yang inovatif dengan mempertimbangkan prioritas keinginan konsumen atau pengguna sebagai dasar menentukan urutan spesifikasi mesin untuk meningkatkan kualitas, efektifitas, dan meningkatkan kapasitas hasil produksi. Metode yang digunakan dalam penelitian ini yaitu metode Quality Function Deployment (QFD) untuk menentukan atribut kebutuhan konsumen terhadap mesin produksi pudak dan tingkat kepentingan, serta ditentukan urutan prioritas spesifikasi mesin dengan metode Analytical Hierachy Process (AHP). Hasil penelitian menghasilkan desain mesin pudak yang mampu memenuhi keinginan UMKM dengan prioritas mesin yang tidak mudah rusak dengan bobot prioritas sebesar 0,252 dan atribut respon teknis yang diprioritaskan yaitu mesin memiliki tombol otomatis dengan nilai keterkaitan sebesar 21.
\end{abstract}

Kata Kunci: AHP, TTG, QFD, UMKM

\section{Abstract}

There are many Micro, Small and Medium Enterprises (MSMEs) for Pudak cake in Gresik, but these MSMEs have several problems, one of which is that in the production process, on average, Appropriate Technology (TTG) has not been touched so that the growth is not optimal because it is still done manually. The purpose of this research is to design an innovative pudak production machine design by considering the priority of consumer or user desires as a basis for determining the sequence of machine specifications to improve quality, effectiveness, and increase production capacity. The method used in this study is the Quality Function Deployment (QFD) method to determine the attributes of consumer needs for pudak production machines and the level of importance, and determine the priority order of machine specifications using the Analytical Hierachy Process (AHP) method. The results of the research resulted in a pudak engine design that was able to meet the needs of MSMEs with a priority of machines that were not easily damaged with a priority weight of 0.252 and prioritized technical response attributes, namely the machine has an automatic button with a linkage value of 21.

Keywords: AHP, TTG, QFD, MSME's

Diterima 21 November 2020; direvisi terakhir 18 Januari 2021; diterbitkan 21 Januari 2021 


\section{PENDAHULUAN}

Usaha Mikro Kecil dan Menengah (UMKM) di Indonesia telah berkontribusi besar terhadap peningkatan perekonomian negara [1]. Maka dari itu pertumbuhan dan perkembangan UMKM di Indonesia perlu untuk diperhatikan dan diberdayakan agar tidak terjadi banyak UMKM yang tutup atau tidak produksi lagi. Berdasarkan data tahun 2015 hingga 2018 terdapat 1,7 juta UMKM menutup usahanya [2]. Permasalahan yang dihadapi oleh UMKM salah satunya faktor kurangnya penguasaan teknologi [3]. Penguasaan teknologi oleh UMKM di era saat ini menjadi faktor penting dalam memenangkan persaingan.

Salah satu UMKM yang hingga saat ini masih bertahan dan sulit berkembang akibat kurangnya penguasaan teknologi yaitu UMKM pembuat Pudak di Kelurahan Lumpur Kabupaten Gresik. Dimana di Kelurahan tersebut beberapa pengrajin masih memproduksi produk secara manual dan sederhana tanpa tersentuh Teknologi Tepat Guna (TTG). Akibatnya kapasitas produksi dan omset perhari menjadi kurang maksimal. TTG merupakan teknologi yang cocok dengan kebutuhan masyarakat sehingga bisa dimanfaatkan pada saat rentang waktu tertentu untuk mencapai tujuan meningkatkan kesejahteraan masyarakat [4].

Berdasarkan penelitian sebelumnya tentang peracangan mesin mnggunakan metode yang berbasis keinginan pelanggan. Pada Sutanto [5] pada penelitiannya terkait mengembangkan desain produk peralatan pembuat adonan roti dengan metode QFD untuk meningkatkan jumlah produksi. Permatadenyn dan Nuryulianti [6] membuat perancangan alat cetak kue risoles dengan metode QFD untuk meningkatkan produktivitas dan kualitas produk. Shobiruddin dan Wulandari [7] menerapkan metode QFD (Quality Function Deployment) untuk desain mesin penggilingan ikan untuk menigkatkan produktivitas petani. Namun, dari ketiga peneltian tersebut tidak menentukan urutan prioritas keinginan konsumen untuk menentukan urutan spesifikasi desain mesin. QFD yaitu alat yang sering digunakan untuk meningkatkan perencanaan produk serta pengembangan proses dan produk [8]. Tujuan QFD yaitu memenuhi harapanharapan pelanggan dan berusaha melampaui harapan-harapan pelanggan [9]. 
Berdasarkan uraian latar belakang dan beberapa penelitian sebelumnya untuk meningkatkan kualitas dan kapasitas produksi UMKM Pudak, maka diperlukan penerapan TTG dalam produksinya. Adapun tujuan dari penelitian yaitu merancang desain mesin produksi kue pudak yang inovatif dengan mempertimbangkan keinginan konsumen dengan metode Quality Function Deployment (QFD). Selain itu dalam perancangan mesin akan mempertimbangkan urutan keinginan konsumen atau pengguna untuk dipertimbangkan dalam perancangan prioritas spesifikasi mesin dengan metode Analytical Hierarchy Process (AHP). AHP adalah adalah prosedur yang berbasis matematis yang sangat baik dan sesuai untuk kondisi evaluasi atribut-atribut kualitatif dalam bentuk pembobotan pada multi kriteria [10].

\section{METODE PENELITIAN}

Penelitian ini dilaksanakan dalam beberapa tahap yaitu tahap pertama dilakukan literature review dengan mempelajari konsep dan teori yang berkaitan dengan topik. Setelah itu tahap kedua yaitu melakukan studi lapangan untuk mengetahui kondisi UMKM pembuat Pudak di Kelurahan Lumpur Kabupaten Gresik. Kemudian tahap ketiga yaitu pengumpulan data wawancara dan data sekunder dari penelitian sebelumnya atau jurnal ilmiah. Tahap keempat yaitu pengolahan data yaitu uji validitas dan reliabilitas dengan software SPSS, serta pengolahan dengan QFD, dan menentukan prioritas kebutuhan pelanggan dengan sistem ranking bobot dengan metode Analytical Hierarchy Process (AHP). Tahap kelima yaitu melakukan analisa hasil pengolahan data. Tahap keenam yaitu menarik kesimpulan.

\section{HASIL DAN PEMBAHASAN}

Pada bagian ini akan dijelaskan hasil penelitian yang dilakukan dan disertai pembahasan dari hasil penelitian. Adapun hasil penelitian dan pemabahasan sebagai berikut.

\section{a. Penentuan Atribut Kebutuhan Konsumen terhadap Mesin Pudak}

Penentuan kebutuhan konsumen tehadap mesin pudak didapatkan dari hasil wawancara dengan 10 pelaku UMKM kue Pudak Gresik. Dari hasil wawancara 
teenyata di dapatkan 9 atribut kebutuhan konsumen.

Tabel 1. Atribut Kebutuhan Konsumen

\begin{tabular}{|l|l|}
\hline No & Atribut Kebutuhan Konsumen \\
\hline 1 & Mesin tidak mudah rusak \\
\hline 2 & Tahan lama \\
\hline 3 & Mudah di operasikan \\
\hline 4 & Mempercepat proses produksi \\
\hline 5 & Efisiensi penggunaan peralatan \\
\hline 6 & Kualitas produk lebih higienis \\
\hline 7 & Ergonomis /nyaman digunakan \\
\hline 8 & Mudah dipindahkan \\
\hline 9 & Harga murah \\
\hline
\end{tabular}

Setelah didapatkan atribut kebutuhan konsumen maka ditentukan nilai dari atribut kebutuhan konsumen dengan skala likert skor 1-4. Penentuan penilaian atribut dilakukan dengan bantuan kuesioner yang diberikan kepada 10 narasumer yaitu pelaku UMKM kue pudak Gresik. Adapun hasil rekapitulasi penilaian atribut terdapat pada tabel 2 .

Tabel 2. Rekapitulasi Kuesioner Penilaian Atribut Kebutuhan Konsumen

\begin{tabular}{|l|l|c|c|c|c|c|}
\hline No & \multicolumn{1}{|c|}{$\begin{array}{c}\text { Atribut Kebutuhan } \\
\text { Konsumen }\end{array}$} & $\begin{array}{c}\text { Kode } \\
\text { Atribut }\end{array}$ & $\begin{array}{c}\text { KP } \\
\text { Skor 1 1 } \\
\text { (orang) }\end{array}$ & $\begin{array}{c}\text { P } \\
\text { Skor 2 } \\
\text { (orang) }\end{array}$ & $\begin{array}{c}\text { SP } \\
\text { Skor 3 3 } \\
\text { (orang) }\end{array}$ & $\begin{array}{c}\text { SPS } \\
\text { Skor 4 } \\
\text { (orang) }\end{array}$ \\
\hline 1 & Mesin tidak mudah rusak & $\mathrm{X} 1$ & 0 & 2 & 3 & 5 \\
\hline 2 & Tahan lama & $\mathrm{X} 2$ & 0 & 1 & 5 & 4 \\
\hline 3 & Mudah di operasikan & $\mathrm{X} 3$ & 0 & 1 & 4 & 5 \\
\hline 4 & Mempercepat proses produksi & $\mathrm{X} 4$ & 0 & 2 & 3 & 5 \\
\hline 5 & Efisiensi penggunaan peralatan & $\mathrm{X} 5$ & 0 & 2 & 3 & 5 \\
\hline 6 & Kualitas produk lebih higienis & $\mathrm{X} 5$ & 0 & 3 & 3 & 4 \\
\hline 7 & Ergonomis /nyaman digunakan & $\mathrm{X} 7$ & 0 & 3 & 1 & 6 \\
\hline 8 & Mudah dipindahkan & $\mathrm{X} 8$ & 0 & 2 & 4 & 4 \\
\hline 9 & Harga murah & $\mathrm{X} 9$ & 0 & 2 & 2 & 6 \\
\hline
\end{tabular}

Keterangan : KP (Tidak Penting), P (Penting), SP (Sangat Penting),SPS (Sangat Penting Sekali).

\section{b. Uji Validitas dan Uji Reliabilitas}

Tabel 3. Hasil Uji Validitas

\begin{tabular}{|c|c|c|c|c|}
\hline $\begin{array}{c}\text { Kode } \\
\text { Atribut }\end{array}$ & $\begin{array}{c}\text { Nilai R } \\
\text { Hitung }\end{array}$ & $\begin{array}{c}\text { Nilai } \\
\mathbf{R} \\
\text { Tabel }\end{array}$ & $\begin{array}{c}\text { Nilai } \\
\text { Sig. }\end{array}$ & $\begin{array}{c}\text { Kepu } \\
\text { tusan }\end{array}$ \\
\hline X1 & 0,814 & 0,632 & 0,004 & Valid \\
\hline X2 & 0,683 & 0,632 & 0,003 & Valid \\
\hline X3 & 0,764 & 0,632 & 0,002 & Valid \\
\hline
\end{tabular}




\begin{tabular}{|l|l|l|l|l|}
\hline X4 & 0,721 & 0,632 & 0,000 & Valid \\
\hline X5 & 0,816 & 0,632 & 0,002 & Valid \\
\hline X6 & 0,734 & 0,632 & 0,001 & Valid \\
\hline X7 & 0,836 & 0,632 & 0,002 & Valid \\
\hline X8 & 0,789 & 0,632 & 0,001 & Valid \\
\hline X9 & 0,727 & 0,632 & 0,000 & Valid \\
\hline
\end{tabular}

Berdasarkan hasil uji validitas dari tabel 3 ternyata semua atribut dinyatakan "valid". Hal tersebut dapat dilihat dari nilai Rhitung > R Tabel (R-Hitung lebih besar dari R-Tabel) dan juga Nilai Sig. tidak lebih besar dari 5\%.

Tabel 4. Hasil Uji Reliabilitas

\begin{tabular}{|r|r|r|}
\hline $\begin{array}{c}\text { Cronbach's } \\
\text { Alpha }\end{array}$ & $\begin{array}{c}\text { Cronbach's Alpha } \\
\text { Based on } \\
\text { Standardized Items }\end{array}$ & N of Items \\
\hline .808 & .803 & 9 \\
\hline
\end{tabular}

Berdasarkan hasil uji reliabilitas pada tabel 4 dengan menggunakan software SPPS, menunjukkan bahwa hasil tersebut dinyatakan "Reliabel". Karena nilai nilai Cronbach alpha sebesar $86 \%$ dimana nilai tersebut lebih besar dari $60 \%$.

\section{c. Penentuan Tingkat Kepentingan Tiap Atribut}

Pada penentuan tingkat kepentingan tiap atribut dilakukan menghitung rata-rata nilai total dari hasil kuesioner penilaian atribut kebutuhan konsumen. Adapun hasil penentuan nilai tingkat kepentingan tiap atribut sebagai berikut.

Tabel 5. Nilai Tingkat Kepentingan

\begin{tabular}{|c|l|l|l|l|l|l|l|l|l|}
\hline Responden ke- & $\mathbf{X 1}$ & $\mathbf{X 2}$ & $\mathbf{X 3}$ & $\mathbf{X 4}$ & $\mathbf{X 5}$ & $\mathbf{X 6}$ & $\mathbf{X 7}$ & $\mathbf{X 8}$ & $\mathbf{X 9}$ \\
\hline 1 & 2 & 3 & 2 & 3 & 3 & 2 & 2 & 2 & 2 \\
\hline 2 & 3 & 3 & 3 & 3 & 3 & 3 & 3 & 2 & 4 \\
\hline 3 & 2 & 2 & 4 & 2 & 4 & 2 & 2 & 4 & 2 \\
\hline 4 & 5 & 3 & 3 & 3 & 2 & 3 & 4 & 3 & 4 \\
\hline 5 & 3 & 4 & 4 & 2 & 3 & 4 & 2 & 4 & 3 \\
\hline 6 & 5 & 4 & 3 & 4 & 2 & 2 & 4 & 3 & 4 \\
\hline 7 & 3 & 3 & 4 & 4 & 4 & 3 & 4 & 4 & 4 \\
\hline 8 & 5 & 4 & 3 & 4 & 4 & 4 & 4 & 4 & 4 \\
\hline 9 & 5 & 4 & 4 & 4 & 4 & 4 & 4 & 3 & 4 \\
\hline 10 & 5 & 3 & 4 & 4 & 4 & 4 & 4 & 3 & 3 \\
\hline TOTAL & $\mathbf{3 8}$ & $\mathbf{3 3}$ & $\mathbf{3 4}$ & $\mathbf{3 3}$ & $\mathbf{3 3}$ & $\mathbf{3 1}$ & $\mathbf{3 3}$ & $\mathbf{3 2}$ & $\mathbf{3 4}$ \\
\hline $\begin{array}{l}\text { Rata-rata Nilai } \\
\text { kepentingan }\end{array}$ & $\mathbf{3 . 8}$ & $\mathbf{3 . 3}$ & $\mathbf{3 . 4}$ & $\mathbf{3 . 3}$ & $\mathbf{3 . 3}$ & $\mathbf{3 . 1}$ & $\mathbf{3 . 3}$ & $\mathbf{3 . 2}$ & $\mathbf{3 . 4}$ \\
\hline
\end{tabular}




\section{d. Penentuan Respon Teknis}

Penentuan respon teknis dilakukan dengan melakukan wawancara dengan produsen atau pembuat mesin dan menggunakan data peneltian sebelumnya serta jurnal ilmiah. Respon teknis merupakan respon terhadap atribut kebutuhan untuk di selaraskan atau dihubungkan agar dalam perancangan mesin dapat menghasilkan spesifikasi mesin yang mampu memenuhi atribut kebutuhan konsumen.

Tabel 6. Respon Teknis

\begin{tabular}{|l|l|}
\hline No & \multicolumn{1}{|c|}{ Respon Teknis } \\
\hline 1 & Bahan rangka baja \\
\hline 2 & Bahan plat aluminium \\
\hline 3 & Tombol otomatis \\
\hline 4 & Pengaturan kecepatan mixer \\
\hline 5 & Bak dan mixer satu rangkaian \\
\hline 6 & Dimensi sesuai anthropometri \\
\hline 7 & Sparepart mudah di cari \\
\hline 8 & Harga bahan cukup terjangkau \\
\hline 9 & Diameter saluran lubang adonan besar \\
\hline
\end{tabular}

\section{e. Pembuatan House of Quality (HOQ)}

Setelah mendapatkan atribut kebutuhan konsumen dan juga respon teknis, maka untuk mengetahui keterkaitannya dibuatkan desain dan perhitungan HOQ. Adapun dalam pembuatan HOQ dalam penelitian ini dilakukan dengan tahapan yaitu:

1) Membuat keterkaitan antara atribut kebutuhan konsumen dengan respon teknis yang tujuannya menjembatani atribut kebutuhan konsumen dengan teknis perancangan mesin. Penentuan keterkaitan tersebut dinyatakan dalam simbol sebagai berikut :

a) Hubungan kuat $(\mathbf{O})$, bobot keterhubungan $=9$

b) Hubungan sedang $(O)$, bobot keterhubungan $=3$

c) Hubungan lemah $(\Delta)$, bobot keterhubungan $=1$

2) Menentukan hubungan antar sesama atribut respon teknis.

Menentukan hubungan antar respon teknis bertujuan untuk mengetahui hubungan kuat, positif, none, atau negative. Hubungan keterkaitan dibuat dalam bentuk simbol sebagai berikut: 


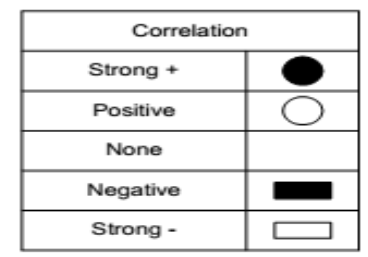

Gambar 1. Simbol hubungan antar respon teknis

\section{3) Sales Point}

Sales point merupakan penilaian yang dimaksudkan untuk memberikan nilai apakah atribut kebutuhan memiliki nilai jual yang tinggi terhadap produk yang akan di buat. Nilai sales point terdiri nilai 1 tidak ada sales point, nilai 1,2 sales point sedang dan nilai 1,5 sales point kuat.

\section{4) Target / Goal}

Nilai target yaitu suatu nilai yang ingin dicapai terhadap tingkat kepuasan terhadap atribut keinginan konsumen terhadap mesin yang akan di buat. Penilaian target didapatkan dari skala likert 1-4 pada pertanyaan atribut kebutuhan konsumen terhadap mesin yang akan dirancang.

5) Nilai improvement ratio

Improvement ratio merupakan nilai rasio yang didapatkan untuk mengetahui seberapa besar perubahan terhadap atribut produk yang akan dirancang.

Tabel 7. Penilaian Goal, Improvement Ratio \& Sales Poin

\begin{tabular}{|c|l|c|c|c|c|}
\hline No & \multicolumn{1}{|c|}{ Kebutuhan Pelanggan } & $\begin{array}{c}\text { Goal } \\
\text { (a) }\end{array}$ & $\begin{array}{c}\text { Tingkat } \\
\text { Kepentingan } \\
\text { (b) }\end{array}$ & $\begin{array}{c}\text { Improvement } \\
\text { Ratio } \\
\text { (a/b) }\end{array}$ & $\begin{array}{c}\text { Sales } \\
\text { Point }\end{array}$ \\
\hline 1 & Mesin tidak mudah rusak & 4 & 3,8 & 1,05 & 1,5 \\
\hline 2 & Tahan lama & 4 & 3,3 & 1,21 & 1,5 \\
\hline 3 & Mudah di operasikan & 4 & 3,4 & 1,18 & 1,5 \\
\hline 4 & Mempercepat proses produksi & 4 & 3,3 & 1,21 & 1,5 \\
\hline 5 & Efisiensi penggunaan peralatan & 4 & 3,3 & 1,21 & 1,2 \\
\hline 6 & Kualitas produk lebih higienis & 4 & 3,1 & 1,29 & 1,2 \\
\hline 7 & Ergonomis /nyaman digunakan & 4 & 3,3 & 1,21 & 1,5 \\
\hline 8 & Mudah dipindahkan & 4 & 3,2 & 1,25 & 1,2 \\
\hline 9 & Harga murah & 4 & 3,4 & 1,18 & 1,2 \\
\hline
\end{tabular}

Setelah mendapatkan goal, improvement ratio dan sales poin kemudian dilakukan penentuan prioritas keinginan pelanggan untuk dipertimbangkan dalam menentukan urutan spesifikasi mesin yang di prioritaskan. Penentuan prioritas kebutuhan pelanggan menggunakan metode AHP. Adapun hasilnya sebagai berikut. 
Tabel 8. Bobot Tiap Kebutuhan Pelanggan

\begin{tabular}{|c|l|c|c|}
\hline No & \multicolumn{1}{|c|}{ Kebutuhan Pelanggan } & Bobot (Weight) & Rangking \\
\hline 1 & Mesin tidak mudah rusak & 0,252 & 1 \\
\hline 2 & Tahan lama & 0,129 & 3 \\
\hline 3 & Mudah di operasikan & 0,159 & 2 \\
\hline 4 & Mempercepat proses produksi & 0,087 & 6 \\
\hline 5 & Efisiensi penggunaan peralatan & 0,091 & 5 \\
\hline 6 & Kualitas produk lebih higienis & 0,063 & 7 \\
\hline 7 & Ergonomis /nyaman digunakan & 0,062 & 8 \\
\hline 8 & Mudah dipendahkan & 0,042 & 9 \\
\hline 9 & Harga murah & 0,115 & 4 \\
\hline
\end{tabular}

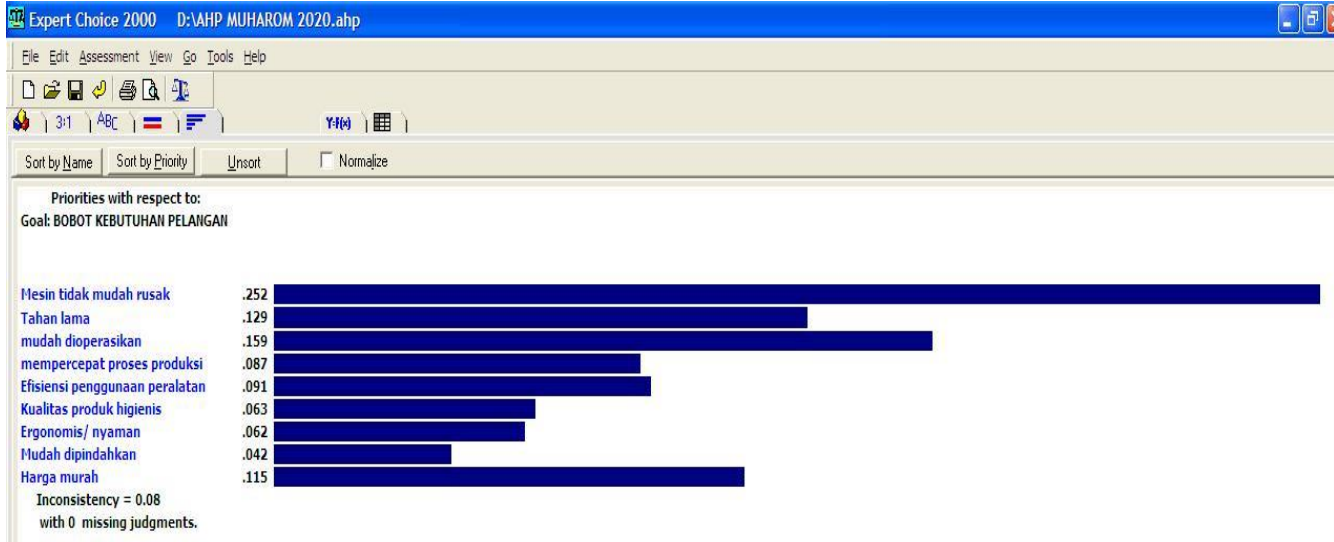

Gambar 2. Perhitungan Bobot Metode AHP Dengan Software Expert Choice

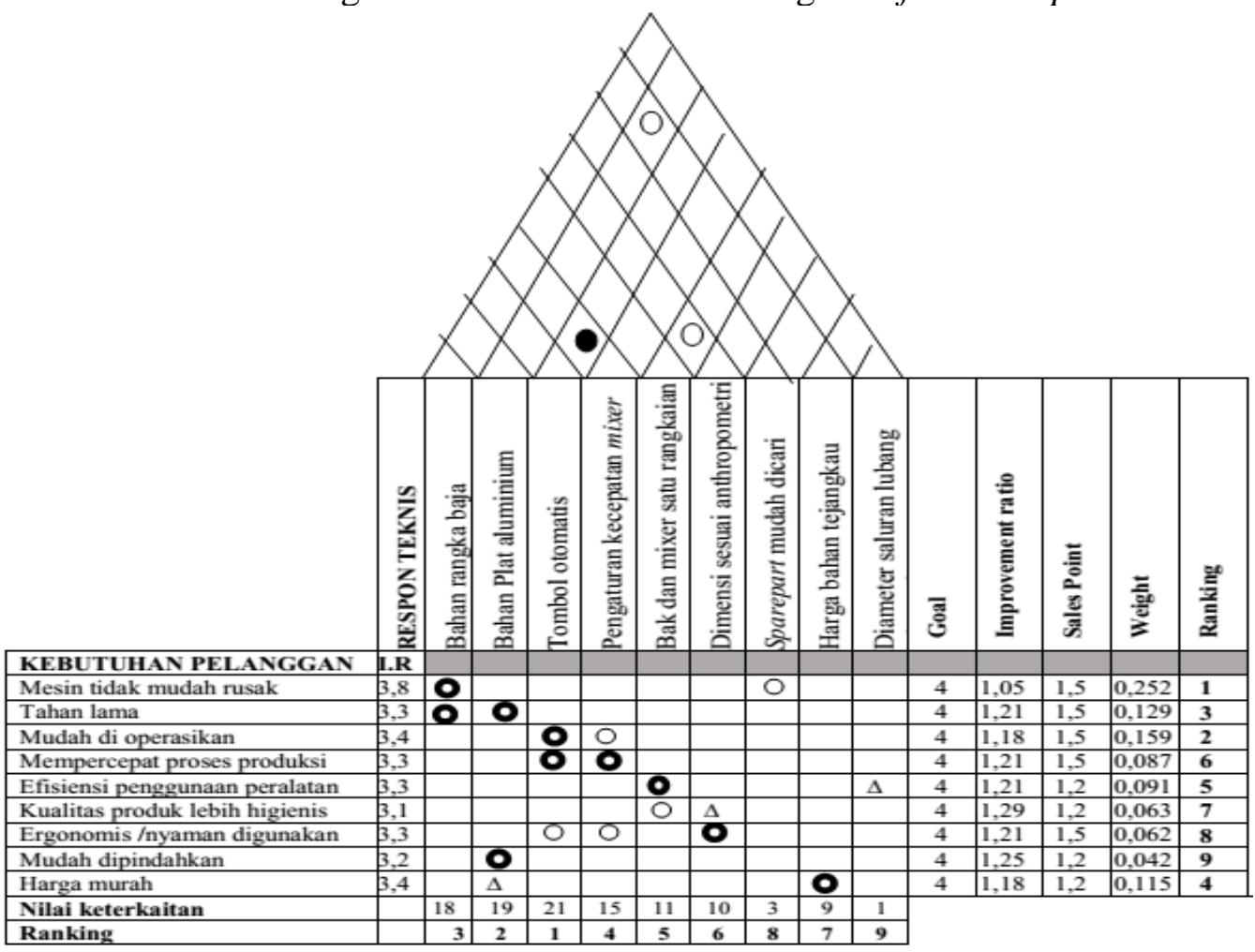

Gambar 3. Hasil House of Quality (HOQ) 


\section{f. Desain Mesin Produksi Kue Pudak Berdasarkan Hasil QFD}

Perancangan desain mesin pembuat kue pudak ini didapatkan dari hasil QFD. Spesifikasi mesin di buat berdasarkan kebutuhan pelanggan dan juga respon teknis yang telah ditentukan. Adapun desain mesin kue pudak sebagai berikut.

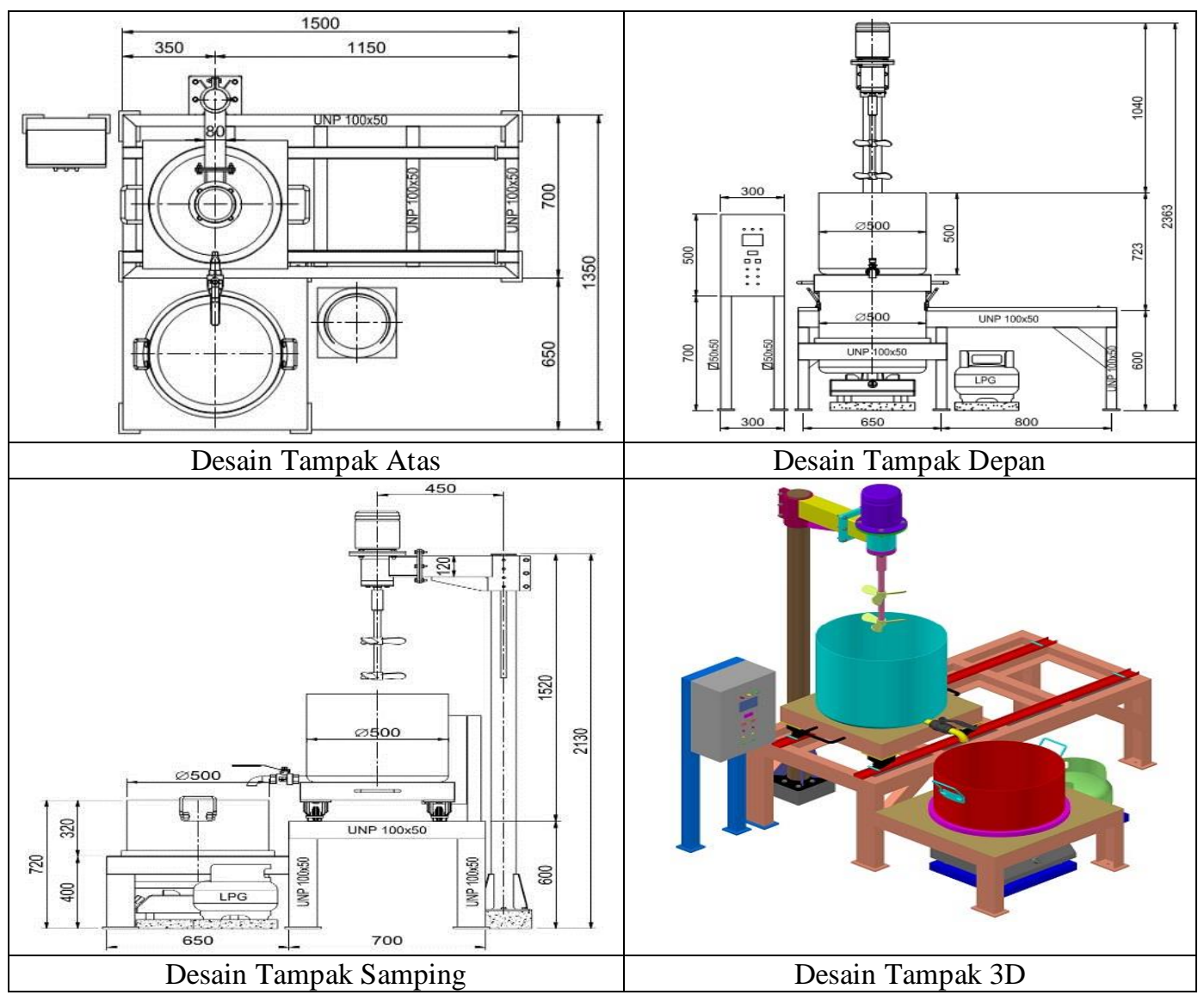

Gambar 4. Desain Mesin Produksi Pudak Hasil QFD

\section{KESIMPULAN}

Berdasarkan hasil penelitian di dapat desain mesin pembuat kue pudak yang mempertimbangkan prioritas keinginan konsumen dengan metode QFD dan AHP. Spesifikasi perancangan desain mesin pudak ditentukan dari hasil prioritas kebutuhan pelanggan dimana prioritas dengan nilai terbesar yaitu pada kebutuhan desain mesin yang tidak mudah rusak dengan nilai bobot sebesar 0,252 dan prioritas terendah pada atribut kebutuhan kosumen yaitu mudah dipindahkan dengan bobot 0,042. Sedangkan hasil analisis atribut respon teknis yang menjadi prioritas utama yaitu pada atribut tombol otomatis karena memiliki keterkaitan yang paling besar terhadap atribut kebutuhan pelanggan dengan nilai keterkaitan 21. Sedangkan prioritas terakhir pada respon teknis yaitu pada atribut diameter 
saluran lubang cairan adonan dengan nilai keterkatan 1. Saran untuk penelitian selanjutnya yaitu perlu adanya kajian lebih mendalam terhadap respon dari pelanggan atau pengguna mesin untuk diidentifikasi kelemahan dari mesin pembuat pudak saat ini untuk tujuan pengembangan mesin pudak selanjutnya.

\section{DAFTAR PUSTAKA}

[1] R. Rita Purwaningsih dan N. Asandimitra Haryono, "Sumber Daya Manusia, Operasional, Pemasaran, Dan Kebijakan Pemerintah Terhadap Kinerja UMKM Di Kota Surabaya," Jurnal Ekonomi dan Bisnis, Vol.12, No.2, pp. 390-409, 2019.

[2] B. Setiaji, "1,7 Juta UMKM Bangkrut, Tak Kuat Bersaing Di Era 4.0," Mentarinews.com, 2019. [Online]. Available: https://mentari.news/2019/04/17-juta-umkm-bangkrut-tak-kuat-bersaing-diera-4-0. [Accessed: 20-Mar-2020].

[3] Hartono dan D. Dwi Hartomo, "Faktor-Faktor Yang Mempengaruhi Perkembangan UMKM Di Surakarta," Jurnal Bisnis \& Manajemen, Vol. 14, No. 1, pp 15-30, 2014.

[4] D. R. Munaf, T. Suseno, R. Indra Janu, dan A. M. Badar, "Peran Teknologi Tepat Guna Untuk Masyarakat Daerah Perbatasan Kasus Propinsi Kepulauan Riau," Jurnal Sosioteknologi, vol. 7, no. 13, pp 329-333, 2008.

[5] A. Sutanto, A. Indra, dan B. Yuliandra, "Pengembangan Desain Produk dengan Metoda QFD: Studi Kasus Desain Peralatan Pembuat Adonan Roti untuk Usaha Skala Kecil," in Prosiding Seminar Nasional Tahunan Teknik Mesin XIV (SNTTM XIV) Banjarmasin, 2015.

[6] A. Permatadenyn dan E. Nuryulianti, "Perancangan Alat Cetak Isi Resoles Dengan Metode QFD (Quality Fuction Deployment) Untuk Meningkatkan Efisiensi dan Efektifitas Pada Home Industry Roti," Jurnal Teknoscienza, vol.1, no.1, pp. 2-13.

[7] A. Shobiruddin dan D. Wulandari, "Penerapan Metode QFD (Quality Function Deployment) Untuk Desain Penggiling Pakan Ikan," Jurnal JRM, vol. 4, no. 2, pp. 181-189, 2017.

[8] S. Amin dan M. Kholil, Six Sigma Quality for Business Improvement, Yogyakarta: Graha Ilmu, 2013.

[9] R. Prabowo dan M. Idris Zoelangga, "Pengembangan Produk Power Charger Portable dengan Menggunakan Metode Quality Function Deployment (QFD)," Jurnal Rekayasa Sistem Industri,vol. 8, no. 1, pp. 55-62, 2019.

[10]T. L. Saaty, The Analytic Hierarchy Process, New York : McGraw- Hill, 1980. 